\title{
Development of Resource Effective and Cleaner Technologies Using the Waste of Plant Raw Materials
}

\section{Galyna Khomych', Galyna Krusir², Oleksandra Horobets', Yuliia Levchenko'", Zoia Gaivoronska'}

1 Department of Food industry technologies and restaurant industry, Poltava University of Economics and Trade, Koval Str., 3, Poltava, 36014, Ukraine

2 Department of Ecology and environmental technologies, Odessa National Academy of Food Technologies, Odessa, Kanatnaya Str., 65039, Ukraine

* Corresponding author's e-mail: yuliya_12@ukr.net

\begin{abstract}
The expediency of implementing a particular technology was determined by selecting the best ones from the point of view of environmental, economic and social aspects. The expediency of implementing a particular technology was determined by selecting the best ones from the point of view of environmental, economic and social aspects. The waste re-use is the second most acceptable technology, after waste prevention or minimization during production. This scientific work is dedicated to the waste re-use in food production. The article presents the results of the research and development of the technologies involving the use of organic waste- pomace of the juice production from Chaenomeles fruits. It was determined that the vegetable waste occupies a significant place among the total amount of food waste. The ways of using the waste from the production of Chaenomeles juice was developed and analyzed, which involve obtaining extract, gelling agent, powder, and the ways of their use in the technology of flour-based products were proposed. It was determined that the use of the powder from the pomace of Chaenomeles is the most effective, which allows not only the maximum use of raw materials, but also to improve the technology of production of flour-based products, shorten the fermentation process, extend the shelf life of the finished products and increase their biological value.
\end{abstract}

Keywords: resource effective and cleaner technologies, waste, Chaenomeles, pomace, extract, powder, gelling agent, yeast raised goods.

\section{INTRODUCTION}

An increase in the number of population and economic growth are provoking unprecedented changes in the planet as they drive the increasing demand for energy, land and water which is so necessary to meet the needs of mankind. According to the international organization Global Footprint Network, over the last 50 years, the environmental footprint (natural resource consumption indicator) has increased by about 190\% (Global Footprint Network 2018, Cristian. 2010). Accordingly, creating a sustainable system of providing population with goods, including food, requires significant changes in production, supply and consumption, first of all by finding and implementing efficient resource-saving and cleaner technologies, thus reducing the anthropogenic pressure on the environment.

Such technologies include the low waste and waste-free production. The problem of waste is one of the key environmental issues and it is even more significant in terms of resources(Andreichenko. 2011). Finding a solution to this problem is of great importance for solving the issues of energy and resource independence of a state, saving the natural material and energy resources, and constitutes an urgent strategic task (priority) of the state policy of each country.

The concept of waste-free technology was formed due to the need to protect the environment from the anthropogenic impact of material 
production. In solving this problem, along with the introduction of means of solid waste, wastewater and gas emissions treatment, improvements in the existing and creation of new eco-friendly industries have become of great importance. This trend is known as the waste-free technology (Characteristics of the impact 2019).

The problem of converting the processing of agricultural raw materials into a waste-free production cycle has two interrelated aspects economic and environmental. The first aspect is related to the expansion of resources through deeper, integrated processing of agricultural raw materials and the application of unused waste as a source for obtaining food, feed and fertilizers. In the food industry, during the production of basic (target) products a significant amount of waste and by-products containing hundreds of thousands of tons of sugar, protein, oil, vitamins and other valuable substances are produced in specialized enterprises. It has been substantiated and proven by science that with the complex use of raw materials, it is possible to use almost all the waste and by-products of the food industry with high efficiency (Petruk et al. 2019).

Another aspect of the problem is closely connected to the environmental factors. The development of the processing industries is accompanied by a continuous increase in the impact of production on the environment. The anthropogenic loads on the biosphere should have reasonable limits, the excess of which leads to the disturbance of equilibrium in nature and to imbalance in ecological systems. Therefore, it is now of particular importance to assess the impact of the food production technologies on the environment. The main way to solve the problem is to develop the waste-free industries (Petruk et al. 2019).

The basis of waste-free production is the complex processing of raw materials with all its components, since the production waste is unused or underused part of the raw material.

The basic principles of waste management are: compliance with the principles of a closedcycle economy; waste management hierarchy; integrated waste management information system; systematization and planning; extended producer responsibility (EPR); integration into the EU waste market and the European waste management system. Implementation of these principles will help to prevent waste generation and to contribute to the maximum recycling, as envisaged by the five-step waste management hierarchy (Stessel. 2012, Zaitseva et al. 2018)

One of the ecological problems is provision of the humanity with clean, quality food rich in biologically active components. Chaenomeles is a new raw material on the Ukrainian market. During the juice production, $50 \%$ of the processed material is pomace, which in its turn contains more than $5 \%$ of organic acids, approximately $2 \%$ of tannins, a high content of ascorbic acid, vitamins $\mathrm{B}_{1}, \mathrm{~B}_{2}$, and also substances of $\mathrm{P}$ - vitamin activity and a large amount of pectins. In addition, they include phosphorus, potassium and calcium. Chaenomeles does not contain fat, sodium, so it is useful in diet, but it is rich in dietary fiber and copper (Fedulova et al. 2009, Sawai-Kuroda et al. 2013).

The analysis of the chemical composition of the Chaenomeles pomace allows foreseeing new directions for the use of Chaenomeles production waste as a food additive in the yeast-containing dough technology, as well as a biologically active supplement to the human diet with the aim of strengthening the immune system and facilitating the proper gastrointestinal tract operation (Fedulova et al. 2009, Sawai-Kuroda et al. 2013). A considerable amount of biologically active substances is contained in the waste, as well as in the skin and in the under skin layer.

It is expedient to use the secondary products of the Chaenomeles processing in the production of the flour-based products for accelerating fermentation and stabilizing the finished product quality indicators, which will enable to eliminate chemical food additives and to obtain cleaner food products(Levchenko et al, 2016).

Thus, taking into account the considerable amount of Chaenomeles pomace in the juice production and its biological value, the research and development of new resource effective and cleaner technologies are of current interest.

\section{MATERIALS AND METHODS}

The materials of the research were the Chaenomeles fruits and wastes of the juice production as well as ready-made flour products from the yeast-containing dough. The determination of the main physicochemical parameters of the raw material was performed according to standardized methods. 
The identification of the phenolic substances contained in the Chaenomeles extracts was determined with the method of high performance liquid chromatography on Agilent Technologies chromatograph (model 1100), which is equipped with a G1379A flowing vacuum degasser, a G1313A automatic injector, a G13116A column thermostat, and a G1316A diode matrix detector. A chromatographic column with size $2.1 \times 150 \mathrm{~mm}$, filled with octadecylsilyl sorbent, granulations $3.5 \mathrm{mcm}$ «ZORBAX-SB C-18», was used for the analysis.

The parameters of detection were set as follows: wavelength $-313 \mathrm{~nm}$ (for phenolic acids and their derivatives), $350 \mathrm{~nm}$ (for glycosides of flavones), $371 \mathrm{~nm}$ (for flavones), $525 \mathrm{~nm}$ (for anthocyanins); for the fluorescence detector, the extinction is $280 \mathrm{~nm}$, the emission is $320 \mathrm{~nm}$ for catechin and epicatechin; scale of measurements 1.0; scanning time $2 \mathrm{sec}$. The spectrum removal parameters are each peak 190-600 nm. The identification of phenolic compounds was performed by retention time of the standards and spectral characteristics (compared with the literature data of high-performance liquid chromatography studies of berries and juices).

The content of organic acids and sugars was determined by means of high performance liquid chromatography on Agilent Technologies chromatograph (model 1100). A carbohydrate chromatographic column with a size of $7.8 \times 300 \mathrm{~mm}$, "Supelcogel-C610H" was used for the analysis. A step-by-step mode of chromatography was established: the feed rate of the mobile phase was $0.5 \mathrm{ml} / \mathrm{min}$; eluent aqueous $0.1 \%$ solution of $\mathrm{H}_{3} \mathrm{PO}_{4}$; working pressure of the eluent $33-36 \mathrm{kPa}$; column thermostat temperature of $30^{\circ} \mathrm{C}$; sample volume $5 \mu 1$.

The parameters of the spectrophotometric detection were set as follows: wavelength $210 \mathrm{~nm}$; width of slit $8 \mathrm{~nm}$; scan time $0.5-1.0 \mathrm{~s}$. The identification of organic acids was carried out at the time of retention of the relevant standards. The sample preparation for the analysis of organic acids in pomace involved weighing approximately $5 \mathrm{~g}$ of the pomace accurate to $0.1 \mathrm{mg}$ for each
$10 \mathrm{~cm}^{3}$ a test tube and adjusting to the mark with water. After $30 \mathrm{~min}$ exposure in the ultrasonic bath, the solution was filtered through a membrane Teflon filter with pore sizes of $0.45 \mu \mathrm{m}$ in the vial for analysis.

The NIST07 and WILEY 2007 mass spectra libraries were used to identify the components, with a total of more than 470000 spectra combined with the AMDIS and NIST identification programs. The method of internal standard was used for the quantitative calculations (Levchenko et al. 2016).

\section{RESULTS AND DISCUSSION}

The Chaenomeles pomace is a compacted mass consisting of peel, seeds and pulp residues. The quality indices of the pomace are slightly different from that of the fresh raw material. The comparative characteristics of the chemical composition of fresh fruits and pomace are given in Table 1.

It has been identified (Table 1) that, in comparison with the raw material, pomace is a valuable source of BADs. The pomace contains a considerable amount of pectic substances, sufficient content of L-ascorbic acid and phenolic substances, which confirms the prospect of their further processing.

A significant proportion of the biologically active substances of Chaenomeles are in the bound state, only a part of them is in cellular juice and when processed, they move into a soluble part. The primary carbohydrates that make up the primary cell wall are cellulose, hemicellulose and pectin. Cellulose microfibers are bound through hemicellulose bridges, forming a cellulose-hemicellulose network that is surrounded by a pectin matrix. The phenolic compounds are preferably localized in the skin and cell wall of the pulp of the raw material (Tkach et al. 2014).

The studies on the fractional composition of organic acids in the extracts showed the presence of malic (16.70 g/100 g DS), citric

Table 1. Physicochemical indicators of quality of raw materials and pomace ofChaenomeles

\begin{tabular}{|c|c|c|c|c|c|}
\hline \multirow{2}{*}{ Raw material name } & \multicolumn{3}{|c|}{ Mass fraction, \% } & \multicolumn{2}{c|}{ Content, mg/100 g } \\
\cline { 2 - 6 } & Dry substances & Titrated acids & Pectin substances & L-ascorbic acid & Phenol substances \\
\hline Chaenomeles & 18.44 & 5.36 & 1.62 & 248.00 & 885.00 \\
\hline Pomace & 22.43 & 4.84 & 1.82 & 86.24 & 628.00 \\
\hline
\end{tabular}


(0.54 g/100 g DS), quinic (5.22 g/100 g DS) and succinic $(0.36 \mathrm{~g} / 100 \mathrm{~g} \mathrm{DS})$ acids. Their content is $50-60 \%$ lower than the juice, but it is sufficient to use them as a vegetable additive in the production of food products, in particular, the products from the yeast-containing dough.

The presence of malic and succinic acid in pomace enables to recommend them for use in the flour technology in order to intensify the fermentation process and improve the organoleptic properties of the finished product. However, in the raw form they should be applied, because the introduction of raw pomace will adversely affect the organoleptic properties of the finished products.

It was found that the pomace obtained after the extraction of juice from the Chaenomeles fruit contains phenolic substances, the fractional composition of which is shown in table 2

It was established (Table 2) that the content of phenolic substances in the extract is higher in comparison with the juice. In particular, the content of procyanidins exceeds by $40 \%$, flavan3 -oils - by $70 \%$, oxycoric acids - by $66 \%$ and flavones - by $75 \%$ their content in juice.

Different ways of further processing of the wastes of juice production of the fruits of Chaenomeles are investigated: extraction, drying and obtaining of jellying juice. The expediency of water extracts, powder and gelling juice for further processing into foodstuffs, considering their valuable chemical composition (Table 3), has been determined.

Pomace is a raw material in which the maximum number of cells is destroyed during the pretreatment of the raw material before pressing and during the juice extraction process. As a result of the conducted studies it was found that the best physicochemical parameters for the extraction of the biologically active complex from the untreated pomace of Chaenomeles were obtained at hydromodules (HM) 1: 3, the extraction temperature was $50{ }^{\circ} \mathrm{C}$; extraction time $-120 \mathrm{~min}$. In the case of extraction of dry Chaenomeles pomace with water, the best results are obtained under the following conditions: hydromodules 1:10; temperature $-50{ }^{\circ} \mathrm{C}$; duration $-120 \mathrm{~min}$.

A rational way of recycling fruit and vegetable raw materials involves drying with a purpose of producing fruit and vegetable powders. The powders from plant raw materials allow expanding the food resources and assortment of food products, because they contain all components of raw materials in a concentrated form. Due to the fact that the moisture content of the dried product is $5-8 \%$, then the biochemical reactions in it are almost completely stopped, allowing a long time for its storage (Petruk et al. 2019).

Table 2. The composition of phenolic substances in the pomace of Chaenomeles

\begin{tabular}{|l|l|c|c|}
\hline \multicolumn{2}{|c|}{ Groups of phenolic substances } & Content, $\mathrm{mg} / 100 \mathrm{~g}$ & \% of PS* content \\
\hline \multirow{4}{*}{ Procyanidins } & $\mathrm{B} 1$ & 13.10 & 2.37 \\
\cline { 2 - 4 } & $\mathrm{B}_{2}$ & 120 & 21.67 \\
\cline { 2 - 4 } & $\mathrm{B}_{3}$ & 24.39 & 4.41 \\
\cline { 2 - 4 } & Pentamer & 12.5 & 2.26 \\
\cline { 2 - 4 } & Trimer & 154.56 & 27.92 \\
\hline \multirow{2}{*}{ Flavan-3-oils and their derivatives } & Catechin & 20.79 & 3.76 \\
\cline { 2 - 4 } & Epicatechin & 197.84 & 35.73 \\
\hline Oxycinnamic acids and their derivatives & Chlorogenic acid & 8.36 & 0.31 \\
\hline & Rutin & 2.11 & 0.38 \\
\hline
\end{tabular}

Table 3. Indicators of quality of secondary products of processing wastes of juice production of Chaenomeles

\begin{tabular}{|l|c|c|c|c|c|}
\hline \multirow{2}{*}{ Raw material name } & \multicolumn{3}{|c|}{ Mass fraction, \% } & \multicolumn{2}{c|}{ Content, mg/100 of dry substances } \\
\cline { 2 - 6 } & Dry substances & Titrated acids & $\begin{array}{c}\text { Pectin } \\
\text { substances }\end{array}$ & L-ascorbic acid & $\begin{array}{c}\text { Phenol } \\
\text { substances }\end{array}$ \\
\hline $\begin{array}{l}\text { Extract of fresh pomace of } \\
\text { Chaenomeles (GM 1:3) }\end{array}$ & 3.00 & 3.20 & 0.56 & 9.68 & 420.00 \\
\hline $\begin{array}{l}\text { Extract of dry pomace of } \\
\text { Chaenomeles (GM 1:10) }\end{array}$ & 5.60 & 3.70 & 0.62 & 17.60 & 550.00 \\
\hline Powder & 93.00 & 4.62 & 7.35 & 119.68 & 580.00 \\
\hline Jellying juice & 14.80 & 4.72 & 1.25 & 164.0 & 720.00 \\
\hline
\end{tabular}


The Chaenomeles pomace remaining after juice extraction was used to investigate the dynamics of the extraction process using an extractant - water.

As a result of the conducted research, the optimal parameters for drying the Chaenomeles pomace in the convection steamer were established: temperature $-60^{\circ} \mathrm{C}$, duration -2 hours, thickness of the layer of pomace at drying $-1.5-2 \mathrm{~cm}$. The pomace was ground after drying. The powder obtained was an unstable mass, heterogeneous in size, with color, taste and aroma characteristic of Chaenomeles. In the grinding batch, the particles up to 160 microns in size predominated. The third direction for processing the Chaenomeles pomace is the production of gelling agents on their basis.

The resulting secondary products of recycling wastes of Chaenomeles juice production can be used in the food industry and restaurant industry as a dietary supplement in the manufacturing of flour-based products, including the products from the yeast-containing dough. Depending on their chemical composition and colloidal state, they may have different effects on the properties of the yeast-containing dough.

The results of the organoleptic evaluation showed that the yeast products with the addition of $1.5 \%$ powder, $30 \%$ extract and $10 \%$ gelling agent received the highest scores according to the results of tasting evaluation. In the production of the yeast-containing dough, there are a number of processes that by connecting with each other form a yeast containing dough with characteristic properties. There are a number of factors influencing the dough fermentation process, the main ones being raw materials.

At the stage of maturation of the dough, there are profound changes in the carbohydrate-amylase and protein-proteinaceous complexes of the flour. As a result, the dough acquires a certain elasticity, springiness, viscosity and plasticity, and it also accumulates the substances that form the taste and aroma of the finished products (Poliakova et al. 2009, Khomych and Horobets 2016).

While determining the effect of additives on the intensity of accumulation of yeast cells in the dough during fermentation (Figure 1), an increase in the number of them in the samples, with the addition of $1.5 \%$ of the powder, was identified, which is caused by the chemical composition of the additive, which promotes the active reproduction and accumulation of yeast cells.

In order to conduct a complex assessment of the impact of the secondary products processing of Chaenomeles on the carbohydrate-amylase complex of flour and processes, which occur during the maturation of the dough, (Figure 2a) and acid accumulation (Figure $2 \mathrm{~b}$ ) during fermentation.

After three hours of dough fermentation, the best results were found in the samples with $1.5 \%$ of powder addition, with the shortest time for the ball to rise and the lifting power of the yeast increasing by $25 \%$. The products of the Chaenomeles processing due to the peculiarities of their chemical composition can influence the life activity of acid-forming bacteria and ensure the production of high quality products.

The value of the titrated acidity in the experimental samples with the addition of the secondary products of the Chaenomeles processing increases by an average of $15 \%$ in comparison with the control. Thus, the samples with the addition of $1.5 \%$ of the Chaenomeles powder after 120 minutes of fermentation had a titrated acidity index, which determines the dough ripeness for further processing.
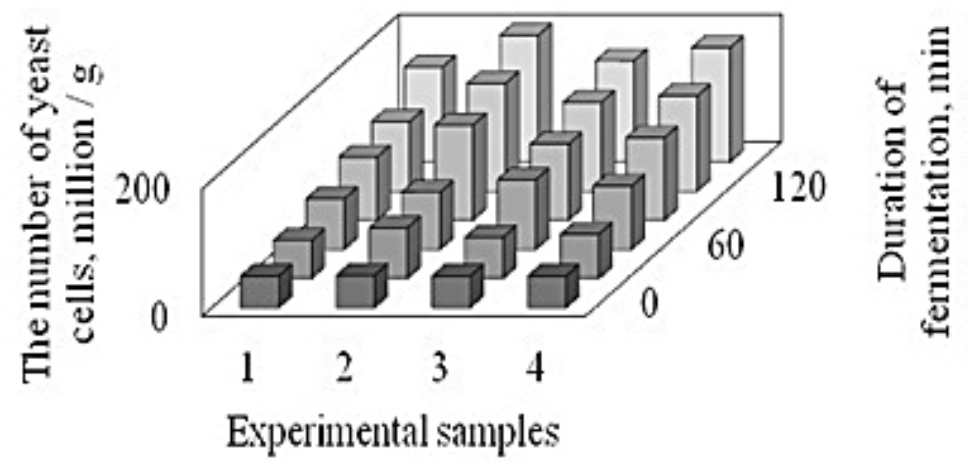

Fig. 1. Effect of recycled products of Chaenomeles on the number of yeast cells (1-control, $2-1.5 \%$ of powder, $3-30 \%$ of extract, $4-10 \%$ of gelling agent) 
a)

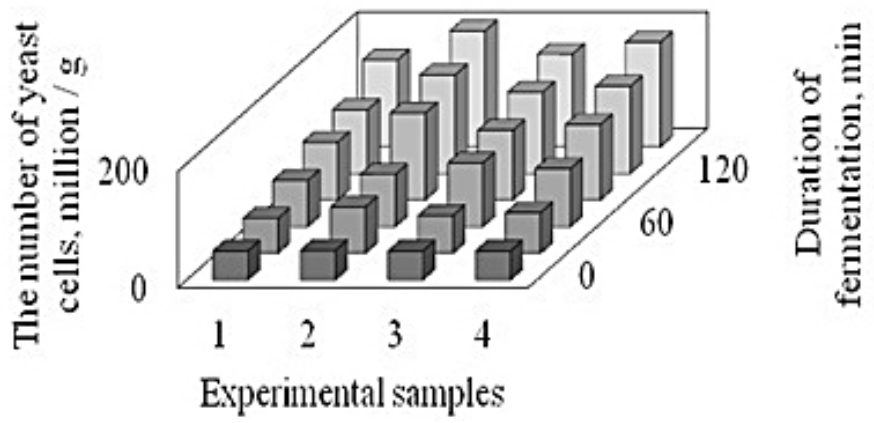

b)

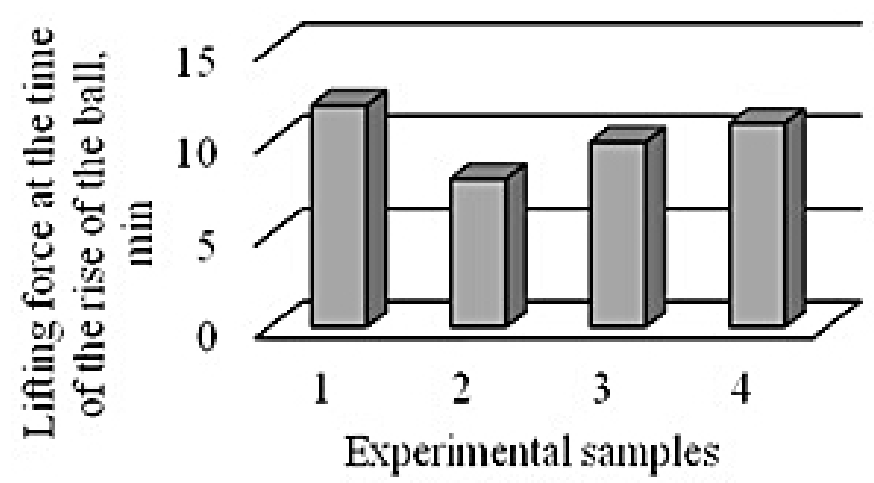

Fig. 2a. Effect of Chaenomeles recycling products on the lifting power of yeast in dough (a), and of yeast in and titrated acidity (b)

( $1-$ control, $2-1.5 \%$ of powder, $3-30 \%$ of extract, $4-10 \%$ of gelling agent)

The conducted research allowed developing the accelerated method of making the yeastcontaining dough with the use of the products of processing of Chaenomeles, which was implemented in the basis of the flour-based foods production.

\section{CONCLUSION}

The obtained experimental results indicate the feasibility of using the Chaenomeles waste (pomace of juice production) in the technology of obtaining food products, like the flour-based products from the yeast-containing dough, which will reduce the negative impact of organic waste on the environment and will allow using the full potential of raw materials.

The use of a powder of Chaenomeles pomace in the technology of producing the flour-based foods is the most efficient and rational, because it enables the maximum use of secondary raw materials in the food production.

The introduction of the yeast-containing dough from $1.5 \%$ Chaenomeles powder to the recipe had a positive effect on the carbohydrate-amylase complex of flour, increased the gas-forming capacity by $19 \%$, the indicator of titratable acidity by $15 \%$, increased the level of organic powder by $45 \%$ acids, pectic substances, minerals, which contributed to the intensification of the process of gas formation, and created the conditions for reducing the total duration of fermentation.

It was determined that when the powder is introduced, there is an increase in the porosity index by $10 \%$, the formability by $16 \%$, and the specific volume - by $18 \%$. The flour-based foods with the addition of powders are become stale slower and retain their properties for 5 days. The use of powders from the Chaenomeles pomace inhibits the development of the potato disease and reduces the overall microbiological contamination of finished flour-based products.

Thus, the use of the powder from the Chaenomeles pomace in the production of the flourbased products allows raising the biological value and consumer properties of the end-product with maximum waste use and reduced the anthropogenic pressure on the environment. 


\section{REFERENCES}

1. Andreichenko, A.V. 2011. The role of waste in building a competitive national economy. Municipal Utilities, (100), 94-101.

2. Characteristics of the impact on the environment of the food industry (2019) URL: http://manyava. org/publ/tekhnoekologija/tekhnoekologija/kharakteristika_vplivu_na_dovkillja_kharchovoji_promislovosti/22-1-0-268 20.06.2019

3. Cristian, O. 2010. Characteristics of the untreated wastewater produced by food indus-try. Analele Universităţii din Oradea, Fascicula: Protecţia Mediului, 15, 709-714.

4. Fedulova, Yu. et al. 2009. Biological features and economic value of Japanese henomeles. Sadovodstvo, Kiev 2009.

5. Global Footprint Network. National Footprint Accounts (2018). URL: http://www.data.footprintnetwork.org

6. Khomych, G. et al. 2016. The study of biologically active substances of Chaenomeles and the products of its processing. Eastern-European Journal of Enterprise Technologies. 4/11 (82), 29-35.

7. Levchenko Y. et al. 2016. The study of main physicalchemical parameters of chaenomeles and products of its processing. Eureka: Life Sciences. 3 (3), 50-56.

8. Khomych, G.P. \& Horobets, O.M. 2016. Flour's technology using chaenomeles. Thesis, New technologies and equipments of food technologies: materials of conference, 19-21.

9. Petruk, V.G. et al. 2019. Environmental protection technologies. P. 4. Technologies of food waste management. Odessa 2019.

10. Poliakova A.V. 2009. Investigation of the influence of vegetable powders on the vuglevody-amylase complex of wheat flour. Thesis, Coverage and technology of food production, 235-240.

11. Sawai-Kuroda, R. et al. 2013. A polyphenol-rich extract from Chaenomeles sinensis (Chinese quince) inhibits influenza A virus infection by preventing primary transcription in vitro, Journal of Ethnopharmacology, 146, 866-872.

12. Stessel, R.I. 2012. Recycling and resource recovery engineering: principles of waste pro-cessing. Springer Science \& Business Media.

13. Tkach, N.I. et al. 2014. Investigation of the chemical composition of the henomeles fruit and its implementation in the juice production. Bulletin of Donetsk National University of Eco-nomics and Trade. Michael Tugan-Baranovsky. Ser. Technical Sciences, (1), 98-104.

14. Zaitseva, V.G., Nesterenko, O.V., \& Onischenko, N.G. 2018. Greening the economy and business in waste management. Scientific Bulletin of Construction, 91 , No. 1, 268-272. 